\title{
LA PÉRDIDA DE LA LENGUA MAPUCHE EN CHILLWE
}

The loss of the mapuche language in Chillwe

\author{
VIKTOR NAQILL GÓMEZ \\ Centro de Estudios Interculturales e Indígenas \\ Pontificia Universidad Católica de Chile (Chile) \\ viktornaqill@gmail.com
}

\section{Resumen}

El artículo tiene por objeto describir las causas que permitieron la permanencia de la lengua mapuche en Chillwe pese a la dominación española, y analizar el proceso de su desaparición. Se propone que el vuelco demográfico que opera a partir de fines del siglo XVIII, con la minorización de la población williche, es una de esas causas, aunque de por sí no decisiva. El segundo factor, quizás más determinante, son las reformas borbónicas, en particular aquellas que apuntan a la unificación lingüística de los dominios españoles mediante la imposición del castellano. Esta política de asimilación lingüística será profundizada con la anexión de Chillwe al naciente Estado nación chileno.

Palabras clave: Chillwe; mapuzugun; asimilación lingüística; Estado nación.

\section{Abstract}

The aim of this article is to describe the causes that made it possible for the Mapuche language to remain firm in Chillwe, in spite of the Spanish domination, and analyse the process of its disappearance. Although it is not a decisive factor, it is proposed that one of the causes is the demographic change that started by the end of the 18th century with the diminution of the Williche population. The second factor, and perhaps the most defining, are the Bourbonic reforms, particularly those that aim at the linguistic unification of the Spanish domains by imposing the Castilian language. This policy of linguistic assimilation will be further developed with the annexation of Chillwe to the rise Chilean State nation.

Key words: Chillwe; mapuzugun; linguistic assimilation; State nation.

El idioma mapuche o mapuzugun (palabra compuesta de mapu: "país" o "tierra", en el sentido de "territorio"; y zugun: "hablar") es la lengua del pueblo mapuche, nación de casi dos millones de personas ${ }^{1}$, y la lengua propia del Wallmapu, el País Mapuche que se extiende por ambos lados de la cordillera de los Andes. También, hasta un pasado no tan lejano, era la lengua propia de Chillwe.

El mapuzugun llegó a ocupar un vasto territorio en el cono sur de América, sirviendo de lingua franca en las pampas del Puelmapu. Muchos españoles nacidos en Chile lo aprendían, lo mismo que los huarpes del Cuyo y los puelche y poyas de la

\footnotetext{
${ }^{1}$ Según el Censo abreviado de 2017, en Chillwe, de 168.185 habitantes, se declararon mapuche 56.421 personas, lo que representa un tercio de la población de la provincia. 
vertiente oriental de los Andes, que los invasores llevaban a su colonia de Chile como mano de obra forzada. En mapuzugun fueron también los primeros contactos entre los jesuitas y los chonos de las Guaitecas, que solían desplazarse hasta Chillwe.

El mapuzugun es hablado hoy por una minoría y según criterio de expertos de la Unesco, es una lengua en peligro de desaparición (Grupo Especial de Expertos sobre las Lenguas en Peligro/UNESCO). En muchos lugares, como en Chillwe, ya desapareció en el siglo pasado. La pérdida de la lengua mapuche en el archipiélago se inscribe así en un proceso global, en curso hoy en todo Wallmapu.

El análisis histórico acerca del mapuzugun puede complementar las investigaciones estrictamente lingüísticas. Asimismo, investigar la pérdida de la lengua en áreas geográficas determinadas, como en este caso Chillwe, podría ser un estímulo para el estudio en otras áreas, lo que con el tiempo nos puede ofrecer una visión global de todo el proceso. Por último, conocer la historia del mapuzugun, su fuerza y prestigio pasados, permite dimensionar la magnitud de lo perdido. La revitalización de la lengua donde aún se practica, y su recuperación en Chillwe o en otros territorios donde se ha perdido, requieren sin duda de esta consciencia histórica.

\section{EL MAPUZUGUN, LENGUA PRINCIPAL BAJO LA COLONIZACIÓN ESPAÑOLA}

Cuando los españoles desembarcan por primera vez en Chillwe, a mediados del siglo XVI, la isla constituye el límite austral del uso del mapuzugun ${ }^{2}$. La población se concentraba en el norte y el oriente del archipiélago, en las costas e islas al abrigo de los vientos oceánicos; la costa del Pacífico - particularmente inhóspita- y del sur, así como el interior-montañoso y cubierto de espeso bosque- estaban despoblados.

De las dos primeras incursiones españolas en Chillwe, ambas en 1558, quedó relación en sendas crónicas. De la primera da cuenta Jerónimo de Vivar, aunque breve, cuando se refiere a la expedición al sur que el gobemador de Chile, García Hurtado de Mendoza, emprendió a partir de Valdivia en el verano de 1558. Según el cronista, una partida de españoles pasó a la isla de Chillwe, "una isla que se parecía grande encima de todas las demás, la cual isla se dice Anquecuy, la cual isla hallaron muy poblada y mucho ganado y maíz y papas..." (De Vivar, 1979, p. 249). La segunda tiene lugar pocos meses después, cuando el navío comandado por Juan de Ojeda, de regreso a Valdivia de una expedición frustrada al estrecho de Magallanes, hace escala en el golfo de los Coronados. Los marinos -españoles radicados en Chile, que manejan en grados diversos el mapuzugun- no encuentran dificultad para comunicarse con la gente del lugar: "Hablaba el capitán con los indios y decía que le entendían bien y que parecía lengua de Mapocho", anota el escribano de la expedición,

\footnotetext{
${ }^{2}$ Si nos atenemos a la Crónica de Vivar, la lengua mapuche era hablada a partir del valle de Combarbalá, por el norte (p. 51).

276 | AlPHA № 53 (Diciembre 2021) PÁGS. 275-291. ISSN 07 16-4254
} 
Miguel de Goizueta. Cuando Ojeda negocia con la población, lo hace "a ratos con lengua a ratos sin ella" (Goizueta, 1852, pp. 91-92). El testimonio de Goizueta, mucho más completo que el de Vivar, confirma una población numerosa, políticamente organizada, con abundantes recursos agrícolas, ganaderos y marinos.

Más al sur, en el archipiélago de los Chonos y canales y costas adyacentes, la población, muy menor en comparación a la williche de Chillwe, tiene un idioma propio, sin relación con el mapuzugun. El mar interior que va del seno de Relonkawi por el norte hasta la entrada del canal Moraleda por el sur era zona de contacto linguístico; Chillwe conserva algunos topónimos en la lengua de los chonos, a pesar de que esta desapareció, junto con sus hablantes que se asimilaron a la población williche, ya en el siglo XVIII.

En 1567 los españoles ocupan Chillwe, construyen el fuerte de Chakaw y fundan Castro. Es el comienzo de la colonización. La población, agrupada por kawi (Guarda, 2002, p. 11), es repartida en encomiendas. Las fuentes de la época destacan lo pobladas que son las islas, pero, por lo general, sin dar cifras. Una excepción es Pedro Mariño de Lobera, quien estima la población, al momento de la instalación del poder español, en unos 20.000 "indios tributarios" (p. 307). En cualquier caso, la caída demográfica que provoca el contacto con los invasores es violenta. A tal punto que, menos de treinta años después, se habla de que sirven a "la ciudad de Castro, la última de Chile, [... ] más de 8.000 indios naturales de la misma isla y de otras circunvecinas" (De Olaverria, 1852, p. 18). Como en muchas partes, las enfermedades traídas por los conquistadores fueron una de las principales causas del derrumbe demográfico. En el caso de Chillwe en particular, hay que añadir la deportación de los isleños llevados como mano de obra a los lavaderos de oro de Chile.

En 1600, cuando la rebelión general desatada por la victoria de Pelantxaru en Kuralaf lleva ya más de un año, Chillwe se rebela. Aprovechando que la mayor parte del ejército había sido enviada al continente para defender Osorno, y la llegada del corsario holandés Balthasar de Cordes, los williche se alían con él y toman Castro. El año siguiente los españoles recuperan el control del territorio, pero, temiendo que la isla sirva nuevamente de escala a corsarios enemigos, el gobernador de Chile, Alonso García Ramón (1846), prevé despoblarla. Considerando una población reducida, según cifras que maneja, a solamente tres mil williche, este estima que, "en el estado que al presente está, será fácil el sacar esta gente de cuajo en cuatro o cinco navíos en un verano"(p. 171). La idea no se puso en práctica, aunque nunca se descartó completamente, volviéndose a plantear cuatro décadas después. ${ }^{3}$ En lo inmediato, los españoles refuerzan los fuertes de

\footnotetext{
${ }^{3}$ Luego de la segunda incursión holandesa a Chillwe, en 1642, los encomenderos pidieron al virrey del Perú que dotara la colonia de las tropas necesarias para su defensa o bien la despoblase. A pesar de que la pretensión de los encomenderos era un traslado a Coquimbo, el virrey, considerando "que entre españoles y mestizos tendría quinientos hombres y más de tres mil indios con que podría poblar a Valdivia", estuvo a punto de despoblar Chillwe con ese objeto (De Rosales, 1877, p. 234).
} 
Kallfüko y Karülmapu, fundados en 1603 con la población evacuada de Osorno, pasando este último a ser la sede del gobierno provincial.

En 1608 llegan los jesuitas, instalándose en Castro los padres Melchor Venegas y Giovanni Battista Ferrofino. Para entonces la independencia mapuche al sur del Biobío se encuentra consolidada, lo que convierte a Chillwe en un enclave sin contacto terrestre con los demás territorios ocupados por los españoles. Alonso González de Nájera se refiere a Castro como un poblado de más de cien casas, con un monasterio, "cuyos habitadores españoles viven en suma pobreza". La causa es, según el cronista, "porque al paso que van faltando los indios por rebeliones y muertes, se les va acabando el sustento y modo de vivir a los nuestros" (González de Nájera, 1866, p. 40). Las cifras de población que dan los misioneros confirman la caída demográfica:

Estos indios de Chiloé hablan la lengua de Chille, serían de diez mil o doce mil almas, algunas de ellas cristianas, pero sin conocimiento casi de Nuestro Señor, son de muy blandos y buenos naturales, suelen traer muchos de ellos a Chile a vender (De Torres, 1609, p. 22).

$\mathrm{Su}$ conocimiento del mapuzugun les permite contactar a los chonos desde temprano, que para entonces algunos también manejan la lengua mapuche. Refiriéndose al cacique chono Pedro del Co, los misioneros observan que:

... por ser él cristiano y haber tenido mucho trato con los de la Isla Grande, sabe y habla bien la lengua general de este reino, y así tuvimos comodidad de hablar con él a la larga e informarnos de todo aquel archipiélago. Traía juntamente consigo otro indio muy ladino en la lengua asimismo general, con el cual comuniqué yo muy a lo largo (Ferrofino).

Como su política era evangelizar en las lenguas locales, los misionarios de la Compañía predican, enseñan y confiesan en mapuzugun. De allí la importancia de dedicarse, desde su arribo al Wallmapu en 1593, a su estudio, aprendizaje y escritura. Chillwe no es una excepción. Andreu Febrès (1964/65), en la introducción de su "Calepino chileno-español" que incluye en su Arte de la lengua general del reino de Chile, escribe:

Finalmente he añadido otras palabras sacadas de otro pequeño calepino, escrito en Chiloé a los principios de este siglo por el padre Gaspar López, [...] las cuales palabras parte he oído, y parte he conocido, que son propias, por ser derivadas, o compuestas de otros verbos (p. 423) ${ }^{4}$.

\footnotetext{
${ }^{4}$ Al revisar el calepino elaborado por Febrès, solo se encuentran dos escasas palabras, michi y kuchi, explicitadas como propias de Chillwe, aunque ambas de origen quechua, incorporadas en el archipiélago, pero no así en el mapuzugun de más al norte. El calepino de López no ha sido encontrado.
}

278 | Alpha № 53 (Diciembre 2021) PÁGS. 275-291. ISSN 07 16-4254 
En 1640, Diego Osorio de Escobar (1819), que será más tarde obispo de Puebla, considerando la posibilidad de sacar "indios amigos" de Chillwe para reconstruir Valdivia, pretende que hay en la provincia más de dos mil (p. 270). Por su parte Diego de Rosales, en un resumen histórico que hace de la disminución de la población de Chillwe, reduce su número, para la misma época, a mil trescientos:

Cuando gobernaba a Chile don Rodrigo de Quiroga, envió a poblar la ciudad de Castro a su yerno Martín Ruiz de Gamboa, el año de 1566, y numerando los indios de estas islas del archipiélago de Chiloé halló de matrícula cincuenta mil indios [...]. Y en una visita que después hizo el capitán Joaquín de Rueda se hallaron solo treinta y seis mil indios tributarios, y que se habían consumido catorce mil. Y en otra visita que hizo el capitán Luis de Salinas, por orden del gobernador Martín García de Loyola, el año de 1593, se numeraron solo doce mil indios, y en veinte y siete años después de la primera matrícula se consumieron treinta y ocho mil indios. Y en la visita del año de 1642 no se hallaron más de mil y trescientos (De Rosales, 1877/78, p. 294).

Si la cifra de 50 mil tributarios al comienzo de la colonización debe ser tomada con cautela, la de mil trescientos para el año 1642 corresponde a una época en que Rosales ya se encuentra en Wallmapu, accediendo por tanto a información de primera mano.

Pese a las dramáticas consecuencias demográficas de la colonización, la lengua se mantiene e incluso es adoptada por los invasores. Cuando la flota de Hendrick Brouwer llegaba a la bahía de Agkü, a fines de 1642, unos españoles les gritan insultos desde la costa "en un idioma que los nuestros no podían entender y que después expresaron en versión castellana. [...] Entendiéndolo, juzgamos no eran indios sino españoles" (Anónimo, pp. 33-34). Hubo capturas de williche, pero no se les pudo interrogar por no saber estos castellano.

Los holandeses se informan que hay cerca de cien encomenderos; el que más tiene para su servicio treinta williche, el que menos cinco. Siempre según la misma fuente, la población williche no supera dos mil personas, luego que una epidemia aniquilara un tercio entre 1637 y 1638 (Anónimo p. 61), de la que hay que descontar las 470 personas que, en acuerdo con los holandeses, embarcaron con ellos para Valdivia (Anónimo, p. 57) cuarto de la población williche de Chillwe. Ya en Valdivia, los holandeses constatan que "la lengua española es tan poco conocida en esta nación, que los nuestros no han hablado aún a nadie que haya entendido lo más mínimo de ella" (Anónimo, p. 81). La incursión holandesa dejó un vocabulario mapuzugun-latín de 472 palabras y 43 frases útiles, de ellas varias interrogativas, necesarias para una comunicación básica (Herckmans). Es razonable

\footnotetext{
${ }^{5}$ Ibíd.,p. 57. Según Rodolfo Urbina (1988, p. 34), la población adulta williche pasa de 4.000 tributarios en 1603 a 3.000 en 1608, a 2.000 a mediados de siglo y a solo 1.500 (lo que corresponde, con sus familias, a 5.500 individuos) en 1684, fecha que para el autor marca el nadir de la población williche de Chillwe.
} 
suponer que la mayor parte del vocabulario haya sido obtenido en Chillwe; es aquí donde los holandeses llegan primero y permanecen más tiempo, cuatro meses.

En el siglo XVIII la colonización hispana en el archipiélago está asentada. Tanto es así que la rebelión de 1712, dirigida contra los encomenderos y sus abusos y no contra el rey y su poder, no puso en riesgo el dominio español (Urbina, 1990). Para entonces la expansión de la lengua en Chillwe es evidente. Cuando John Byron arriba a la isla en 1742, luego de su naufragio en el archipiélago Guayaneco, destaca la vitalidad y prestigio del mapuzugun: "Aquí se habla mucho la lengua india, aun entre los mismos españoles; dicen que la encuentran más bonita que su propio idioma" (p. 116).

El obispo de Concepción Pedro Felipe de Azúa señala en 1744 que el archipiélago "compone su matrícula de más de seis mil españoles y mestizos [...] que se hallan mezclados con los diez mil indios matriculados" (p. 529). Con casi dos tercios de la población, los mapuche son mayoritarios. Aislada de sus connacionales, la minoría de origen español no solo ha adoptado el idioma sino también los hábitos locales. El gobernador Narciso de Santa María se queja en 1755 que los españoles...

... observan algunas costumbres de los indios que no se les puede quitar. Usan dos lenguas, la castellana, muy mal hablada, y la veliche -que es la general de los indios de Chile, con poca diferencia- muy bien generalmente los nobles que la gente común, pues todos la frecuentan más que la castellana, así hombres como mujeres (p. 272).

\section{EL DEBILITAMIENTO DEL MAPUZUGUN}

A fines del siglo XVIII el mapuzugun sigue siendo la lengua principal de Chillwe. Refiriéndose a los españoles, José de Moraleda (1786) observa que:

Usan dos idiomas, castellano y veliche; el primero con incultura y grosera impersonalidad, al contrario, el segundo, con bastante elocuencia, según estoy informado. El veliche se puede considerar casi el dominante de la provincia, y es, con muy corta diferencia, el general de los indios de Chile (p. 207).

Podemos interrogarnos acerca de lo que son, en ese momento, el castellano como el mapuzungun en Chillwe. En el caso de este último, los primeros signos de debilitamiento aparecen ya desde mediados del siglo. Es claro en lo que se refiere a su estatus, menos evidente a nivel del corpus de la lengua. El jesuita José García (1800) escribía, refiriéndose a la situación existente en 1768:

Los isleños de Chiloé usan un lenguaje muy corrompido con muchísimas palabras españolas que han adoptado y que declinan y conjugan según la sintaxis del idioma araucano. De este es dialecto la lengua chilena, aunque alterada o corrompida con palabras forasteras, como he dicho (p. 127). 
Es oportuno preguntarse aquí también, qué entiende García por "lenguaje corrompido". Los préstamos lingüísticos no pueden ser entendidos de manera tan drástica como corrupción de la lengua y, por lo que él dice, la sintaxis no ha sido alterada. Lo que sí parece más claro, por el contrario, es el cambio en el estatus de la lengua, constatándose el progresivo desplazamiento de la lengua propia por la lengua del colonizador. El franciscano Pedro González de Agüeros escribe en 1791:

El idioma que se habla en toda aquella provincia, así entre españoles como indios, es el general de aquel reino, que nombran veliche; pero los más acostumbran ya nuestro castellano, aunque para el acto de la confesión mejor se explican los indios y muchos españoles en su natural idioma, y con particularidad los que habitan en las islas más apartadas de comunicación (González, 1791, pp. 110-111).

En un informe de 1773, el gobernador Carlos de Beranger calcula la población de la provincia, con sus tres curatos de Castro, Chakaw (con sede en Agkü) y Kallfüko, en 19.549 habitantes. De estos, 10.627 son españoles (54\%) y 8.992 williche (46\%). Beranger precisa que en "indios" se ha agregado 190 chonos y waywenes, cifra sin relevancia para el total (50). Por su parte, González de Agüeros (1898), dando como fuente el padrón de 1780, habla de 23.216 habitantes, repartidos entre 11.985 españoles $(51,62 \%)$ y 11.231 williche (48,38 \%) (p. 183). En 1784, el intendente Francisco Hurtado realiza un empadronamiento riguroso de la población, la que fue individualizada con sus nombres. El resultado fue de 26.703 habitantes, de los que 15.076 son españoles $(56,45 \%)$ y 11.627 williche $(43,54 \%)$ (Silva, 1953$)$. La población williche comienza a ser minoritaria. Si bien es un dato importante, no es decisivo desde el punto de vista de la situación lingüística, ya que el mapuzugun era usado tanto por mapuche como españoles. El vuelco demográfico tendrá su impacto más tarde, bajo administración del Estado chileno, el que impondrá en definitiva el castellano.

En España, el cambio dinástico de 1700 abre un proceso de unificación y centralización del Estado que tendrá importantes consecuencias tanto en la península como en el imperio. Las "reformas borbónicas", con sus profundas transformaciones políticas y administrativas, conciernen también al plano lingüístico. Para el Estado absolutista, el objetivo no es solo cristianizar, sino también hispanizar. Esto es, la imposición del castellano para unificar lingüísticamente a la población, de la misma manera que el catolicismo la unifica en el plano religioso. En 1713 se funda la Real Academia Española, que en 1726 publica el primer volumen de su Diccionario de la lengua castellana. En 1770, respondiendo a una demanda del arzobispo de México, una real cédula de Carlos III establece varias medidas a ser aplicadas en el conjunto de los territorios españoles, "para que de una vez se llegue a conseguir el que se extingan los diferentes idiomas de que se usa en los mismos dominios y solo se hable el castellano" (Reino de España, p. 51). En las instrucciones que recibe el gobernador Pedro de Cañaveral cuando se le destina al cargo en 1789, la primera le recuerda que... 
... siendo uno de los principales encargos que por las leyes y posteriores reales cédulas están hechos a los jefes seculares de Indias y prelados eclesiásticos, la enseñanza de la lengua castellana, tendrá el gobernador de Chiloé un particular cuidado de que se enseñe y propague entre todos aquellos vasallos por lo mucho que interesa se asemejen en lenguaje, religión y costumbres a la metrópoli. (Reino de España, 1789).

En condiciones cada vez más adversas, los hablantes circunscriben el uso del mapuzugun en los espacios propios williche. José de Moraleda (1786) da cuenta que en los kawiñ se recuerda, "con una canción en idioma veliche, a que llaman purru, ya con llanto, ya con furia, según lo pide el verso, la memoria de su servidumbre o ajena dominación" (p. 210)6.

Otro factor de importancia en la marginación del mapuzugun es la expulsión de los jesuitas, que en Chillwe se ejecutó en 1768. Los misionarios de la Compañía de Jesús son reemplazados por los franciscanos de San Ildefonso de Chillán. Estos llegan en 1769, pero solo por dos años, siendo a su vez reemplazados en 1771 por el Colegio Franciscano de Santa Rosa de Ocopa. La mayor parte de los nuevos misioneros desconoce la lengua, que además ya no es requisito para su labor. El mapuzugun perdió así un espacio que durante ciento sesenta años había contribuido a su conservación.

\section{LA ANEXIÓN DE CHILLWE Y LA PÉRDIDA DE LA LENGUA}

En enero de 1826Chile ocupa Chillwe. Antes de finalizar el mes se firma el tratado de anexión (Chillwe no formaba parte de la capitanía general de Chile, dependiendo de manera directa del virreinato del Perú), conocido como Tratado de Tantawko, y se crea la provincia de Chiloé, que abarca hasta el cabo de Hornos por el sur. En el primer censo de la República de 1834-1835, Chillwe aparece con 43.832 habitantes, aunque los datos relativos a la provincia, que incluye los departamentos de Karülmapu y Kalfüko, datan en realidad de 18317. El censo no hace distinción entre "españoles" e "indios" (Urízar Garfias, 1835,pp. 171-172).

En noviembre de 1834 llega a Chillwe Charles Darwin. El joven naturalista, junto con dejarnos una visión panorámica de la isla en los años que siguen a la anexión, ofrece unas breves pero interesantes observaciones respecto de la población williche y su lengua. De un viaje a las islas de la costa oriental, entrega la siguiente información:

\footnotetext{
${ }^{6}$ Cuando Moraleda habla de purru puede que se refiera al conjunto de canto y baile, ya que baile en mapuzugun es puru y bailar purun.

${ }^{7}$ Por carencias en la ejecución del censo de 1834-1835, los resultados correspondientes a Chillwe fueron tomados de un censo de 1831.

282 | AlPHA № 53 (DiCIEMBRE 2021) PÁGS. 275-291. ISSN 07 16-4254
} 
Al desembarcar, a eso del mediodía, vimos una familia de pura raza india. [...] El grupo de que hablo sabía muy poco español, y se hablaban en su propia lengua. [...] Más al sur vimos a muchos indios puros, $\mathrm{y}$, de hecho, todos los habitantes de algunas islitas conservan sus apellidos indios. Según el censo de 1832 [sic], había en Chiloé y sus dependencias 42.000 almas: el mayor número parece ser de sangre mezclada; 11.000 tienen apellidos indios, pero probablemente no todos son de pura raza (t. II, 33).

Según los datos que maneja Darwin, un cuarto de la población de la provincia conservaría el apellido mapuche. Unos días después, al viajar a Williñko, observa que, en la localidad, situada a orillas del lago del mismo nombre, "todos los habitantes parecen ser indios". Y, al cruzar en dallka de Williñko a Kukaw, comenta que "el remero principal charlaba en indio" (pp. 59-60). Ya al final de su estadía en Chillwe, Darwin realiza una excursión a punta Wechukuykuy:

Llevé conmigo un guía que conocía demasiado bien el país, porque se empeñó en decirme los interminables nombres indios que había para cada pequeña punta, riachuelo y abra. De igual modo que en Tierra del Fuego, el lenguaje indio parece prestarse admirablemente a denominar los accidentes más triviales del terreno (p. 63).

El mapuzugun se mantiene, pero la disglosia imperante se acentúa con el desarrollo del sistema escolar y del aparato del Estado. Mientras el castellano se consolida con la escuela y la administración, el mapuzugun queda arrinconado en los campos, en el hogar y los mercados.

La educación, que durante el régimen español estaba en manos de órdenes religiosas y tenía poca cobertura, adquiere un fuerte impulso. Pese a su marginalidad geográfica y política, Chillwe es, a mediados del siglo XIX, la provincia con mayor número de escuelas en proporción a su población, más que Santiago y Valparaíso. En 1828 tiene menos de una veintena, pero en 1854 hay 18 establecimientos fiscales y 74 particulares, asistiendo a los primeros 1.264 alumnos y 2.538 a los segundos, dando un total de asistencia de 3.802 (Suárez, 1854, p. 307). La particularidad cultural y educacional del archipiélago no escapa a Carlos García Huidobro, un viajero de Santiago que visita la provincia:

El amor por la cultura intelectual se halla generalmente extendido, aun hasta en las últimas clases de la sociedad de toda la isla; en mi viaje al interior tuve ocasión de ver las escuelas de algunas parroquias y la concurrencia numerosa de alumnos, que atendiendo a la escasez de la población excede y en mucho a la de las provincias del norte (p. 454).

Que la pérdida del mapuzugun sea un fenómeno que afecta no solo a la población mapuche sino también a la española, refuerza la posibilidad que, por lo menos en la última etapa del proceso de asimilación lingüística, la escuela haya jugado un papel fundamental. 
Tanto más cuanto la fuerte escolaridad y el alto nivel de alfabetización relativos de Chillwe conciernen a todos, españoles como mapuche.

En el mismo periodo se refuerza también la presencia del Estado y su burocracia. La población se ve confrontada cada vez más a trámites y gestiones, en persona o por escrito, que son siempre en castellano. Las transformaciones económicas y sociales van también en el mismo sentido, con la apertura al resto del país que también se hace en castellano. Estas son fuerzas que actúan por sí mismas, sin que sea necesaria la intervención de los gobernantes. En tal dinámica histórica, excluida de la escuela y de la administración, sin conexión con el Wallmapu independiente, con cada vez menos hablantes y sin ninguna protección, la lengua mapuche, ahora además discriminada en lo social y que difícilmente podía mantenerse en Chillwe.

En la segunda mitad del siglo XIX el retroceso del mapuzugun es general. Cuando Francisco Vidal Gormaz visita Puluki en 1871, la principal isla del archipiélago de Kallfüko tiene no menos de 2.100 habitantes. De estos, unos 700 son williche, los que, según el marino, "todos hablan castellano, muy pocos el huilliche". Unos cuantos párrafos más adelante es lapidario: los williche de Puluki son "indios tan solo por su tipo característico y su ignorancia, pues todos hablan el español ignorando el huilliche, su antiguo idioma" (Vidal, 1872, pp. 30-31). A fines de siglo solo encontramos "bolsones lingüísticos", como la Costa de Payos, el eje Williñko-Kukaw y las islas Fütachawke. El diagnóstico de Alejandro Cañas Pinochet, una de las personas que más largamente se abocó al estudio de la lengua mapuzungun de chillwe, no es alentador:

Es algo particular lo que sucede entre los indios veliches o chilotes. Contra lo que en todos los pueblos se ve, la persistencia de la raza y de la lengua, entre los indios veliches desaparece rápidamente en su propio suelo, en su exclusivo ambiente, sin otras influencias que la del tiempo y de la raza y lengua castellana que aprenden en la escuela y en el trato con los descendientes de españoles. En el día, el veliche lo hablan los más ancianos que habitan las islas de Apio, Alao y Chaulinec y la reducida población del rancherío y costa de Cucao, en la isla de Chiloé, según lo observamos en nuestro paseo por esta costa en 1887 (Cañas, 1907 a, p. 5 nota).

El uso de la lengua es ocasional, y el número de hablantes o quienes tienen un conocimiento de la lengua, reducido. "En el camino de Chonchi a Quirlen tuve la suerte de hacer conocimiento con un chilote que sabía el idioma indio", cuenta Federico Philippi de su viaje a Chillwe de 1880 (p. 96). Su expresión "tuve la suerte" denota hasta qué punto el uso social de la lengua estaba disminuido.

La situación del mapuzugun en Chillwe en el siglo XIX es difícil de determinar. El fenómeno de la pérdida del idioma es evidente, y las fuentes dan cuenta de ello, pero no permiten describir los grados de uso o desaparición en cada momento o lugar. Nuestras fuentes son sobre todo viajeros o exploradores que solo de manera transitoria y por poco 
tiempo estaban en la zona, por lo que difícilmente pueden tener una visión de conjunto. Y, sobre todo, no hablan mapuzugun.

Como suele mostrar la dinámica de la pérdida de una lengua, en la medida que la lengua dominante se expande, la lengua minorizada tiende a replegarse en ciertos espacios y contextos, como el ritual. En el denominado "proceso de los brujos de Chiloé", en 1881, el testigo Pedro Antonio Güichapane cuenta en su declaración que un denunciado "tomó un vaso con agua y dentro de él puso una piedra [...], siendo Panichine el que hizo esto, y este comenzó a romancear en veliche, fijándose en el vaso, así como que trataba de descubrir a la persona que tenía enfermo a Colipichun" (Juzgado de Ancud, 1960, p. 148).

Ciertos estilos de canto (para algunos, de poesía), como los kollaq, ${ }^{8}$ utilizados en los paseos de visitas o kemun, también se hacen en la lengua. De estos nos ha quedado un importante legado con la recopilación de veintiocho kollaq hecha por Juan Elías Nekul, o como se llamaría después, Elías Carrera. Publicados por primera vez por Alejandro Cañas Pinochet, aunque acompañados de una traducción suya completamente fantasiosa (pese a tener una versión castellana del mismo Nekul), estos kollaq constituyen documentos únicos.

Los datos referentes a la vida de Nekul son escasos. Cañas Pinochet aporta algunos, y en un reciente trabajo se entregan otros pocos ${ }^{9}$. En las notas que acompañan su publicación de los kollaq, Cañas Pinochet describe a Nekul como "nacido y residente en la isla de Cahuach; hombre inteligente y serio, de gran prestigio entre los de su raza". Resalta que "ha desempeñado en la municipalidad de la comuna de Quenac las funciones de municipal, llevado a esta corporación por el voto unánime de sus connacionales, los indios de la comuna, quienes por saber leer y escribir, ejercen el derecho electoral..." (Cañas, 1907 c, p. 132 nota). Sobre todo, deja en claro la autoría de Nekul en relación con la recopilación y escritura de los kollaq: "Toda la poesía veliche, como he dicho, ha sido recogida por don Juan Elías Carrera (Necul) y escrita de su puño y letra". Por él sabemos también que Nekul "ha hablado esta lengua [veliche] y la ha escrito desde su infancia" (Cañas, 1907 b, p. 25 nota). Respecto del momento en el que Cañas Pinochet recibió los apuntes originales, solo podemos estimar, a base de lo que afirma Rudolf Lenz en un escrito, que fue a más tardar en $1897^{10}$. No sabemos cuánto tiempo antes habían sido redactados, pero son probablemente los primeros textos en ser recopilados en lengua mapuche en un ciclo de registro y edición que se prolonga hasta 1934. Nekul emerge así, como el primer recopilador y escritor entre decenas de colaboradores mapuche de los

\footnotetext{
${ }^{8}$ Kollaq en otros territorios de Wallmapu, está asociado a koyawtun, estilo discursivo protocolar de parlamentos.

${ }^{9}$ La conservación de una copia de los manuscritos originales por Rudolf Lenz permitió recientemente una nueva edición, esta vez con una nueva traducción de los editores. Ver Antipani \& Lincofil.

${ }^{10}$ Según Lenz, hacía más de quince años que Cañas Pinochet le había prestado los manuscritos y traducciones originales, de los que había guardado copia (p. 760).
} 
trabajos de Rudolf Lenz, Félix de Augusta, Tomás Guevara, Robert Lehmann-Nietzshe, Ernesto Wilhelm de Moesbach o Sigifredo de Fraunhaüsl.

La lengua se mantiene en el vocabulario relacionado con la labranza de maderas, en particular del lhawal o alerce, que los chillweche van a buscar en el seno de Relonkawi y fiordos de la cordillera. Vidal Gormaz ofrece, a base de las informaciones del práctico Manuel Téllez que le sirve de guía, una hermosa y detallada descripción de las expresiones que los tableros utilizan para referirse a este árbol y su explotación. Nos limitamos aquí a dar un pequeño extracto:

El tablero chilote distingue el alerce por diversos nombres, según su naturaleza, situación, etc., nombres de ordinario veliches. Al descogollado lo llaman cudecude; al desgajado o pobre de copa, cude; al árbol seco, cude petriu; a los de corta edad, palos verdes; a los viejos que tienen dañado algún lado, cancañ; a los tronchados por mitad, ya sea por los vientos o por estar dañados, muchung; al derribado de raíz, regañato; el que por haber sido tronchado tiene una astilla aguda pendiente de su tronco, se le denomina ala; el árbol que crece inclinado sobre el horizonte por alguna causa local, se le llama huiñoy, el que tiene su tronco irregular, grosero y deforme, pollera quechu; cuando dos árboles crecen unidos siendo el uno menor que el compañero, peñeñg; y cuando la planta forma dos piernas o troncos siendo un solo árbol, chanhuay. Estas variantes si bien no distinguen las maderas que se pueden sacar de los troncos, les sirve a los tableros para apreciar el grado de utilidad que deben esperar de ellos (Vidal, 1871, p. 67).

El mapuzugun perdura en la flora autóctona y, en menor medida, en la fauna. Las plantas medicinales conservan sus denominaciones mapuche, así como aquellas utilizadas para teñir (Juliet, Vásquez). Plantas que en otras partes son conocidas con nombre castellano, guardan en Chillwe su denominación original. El naturalista de la expedición de Ramón Serrano al río Palena en 1887 observa que una ribesiácea que encontraban con frecuencia era designada como parrilla por el personal que venía del norte, mientras que los que eran de Chillwe la llamaban mulul (Delfín, 1888, p. 151) ${ }^{11}$.

Finalmente, la lengua propia de Chillwe tiene su manifestación más evidente en la geografia. Un explorador, Roberto Maldonado, escribe en un informe "que la generalidad de los nombres [de los campos de Kikawi] pertenecen a la lengua huilliche, con sonidos guturales que nos hacía difícil escribirlos en castellano. Sobre esta materia -añade- no hemos omitido atención, como medio de restablecer, siquiera en parte, el tecnicismo geográfico indígena, que suponemos una variación geográfica del antiguo araucano"

\footnotetext{
${ }^{11}$ Cuando la expedición se encuentra con gente que identifican como pewenche, se pueden comunicar con ellos gracias a la presencia de un marinero que entiende la lengua mapuche. No se explicita que sea de Chillwe, pero es muy probable. Por la detallada información obtenida no se trata de una comunicación elemental sino extensa, posible solo por dos hablantes (Delfín, 1888, pp. 628-629).

286 | AlpHA № 53 (DiCIEMBRE 2021) PÁGS. 275-291. ISSN 07 16-4254
} 
(Maldonado, 1898, p. 99). Más allá del territorio de presencia ancestral mapuche, la toponimia en mapuzugun se proyecta gracias a los tableros de Chillwe que desde el siglo XIX frecuentan la zona, en el antiguo país de los chonos ${ }^{12}$.

Los sonidos propios de la lengua todavía se escuchan, pero todos los testimonios consignan el retroceso que han producido en el uso del mapuzugun más de dos siglos y medio de dominación colonial española y casi un siglo de asimilación estatonacional chilena. Francisco Cavada (1914) nota que la palabra Chiloé debería ser escrita y pronunciada Chilhue, "como aún pronuncian los indios civilizados de la provincia" (p. 261). Sin embargo, advierte:

Mas, no se crea que el dialecto provincial que hemos estudiado y ordenado a está en todo su vigor a lo menos en el elemento vulgar de la provincia, no: las nuevas generaciones formadas en el ambiente de la vida moderna y más ilustradas a causa de la creciente difusión de la enseñanza primaria y de las nuevas vías abiertas al comercio e industria de la provincia, van echando al olvido las viejas palabras veliches y de los indianismos de él derivados [...]. Aun los mismos viejos indígenas [...] tienen a menos valerse de aquella lengua y aun de estos en presencia de personas de más valer o de mayor representación social, y hasta sonríen, entre risueños y corridos, al oílos en boca de estos últimos (pp. 264-265).

En las postrimerías del siglo, en muy escasas familias y en lugares apartados del archipiélago, nació aun una generación que tuvo como lengua materna el mapuzugun. Sería la última. "A principio del siglo pasado el huilliche era aún el idioma dominante y el general de los indígenas", escribe Alfred Weber, quien fuera inspector de colonización de Llankiwe y Chillwe. El contraste con el siglo XX que comienza es patente: solo "en algunas partes del sudeste de la Isla Grande, en Payos, y en las islas Chauques se habla aún este idioma", constata (p. 7). En la agonía de la lengua mapuche en Chillwe, Cañas Pinochet, que compartió con algunos de sus últimos hablantes, escribe con pesar:

Hasta hace poco había en Chiloé, en las islas de Alao, Apiao y Chaulinec, algunos ancianos que hablaban el veliche, y yo tuve oportunidad, en algunos de los muchos viajes que por el archipiélago hice, de conocerlos. Mis últimas informaciones me dicen que esos ancianos han muerto y que el veliche ha muerto con ellos (Cañas, 1905,25 nota).

A nuestro juicio, la pérdida del mapuzugun relativiza el concepto de sincretismo con que a menudo se describe la cultura de la sociedad insular. En Chillwe, en el plano lingüístico, no hubo sincretismo sino asimilación. Es opinión común decir que se habla

\footnotetext{
12 Enrique Simpson (1875), de la Marina chilena, confeccionó en 1871 una lista de 64 palabras en "payo y antiguo chono" (p. 104); se trata, en realidad, de términos correspondientes al mapuzugun de Chillwe, que aparecen, como el autor lo indica, en denominaciones de puntos geográficos.
} 
un castellano particular, con muchas palabras que vienen del mapuzugun. Es verdad, pero es un castellano particular y no un mapuzugun particular.

La lengua mapuche quedó arraigada en muchas expresiones populares, en la culinaria, en los apellidos de miles de familias, y muy firme y masivamente en la geografía. Pero desapareció como idioma trasmisor de la cultura mapuche propia y particular de Chillwe.

\section{OBRAS CITADAS}

Antipani, Hugo y Edward Lincofil (eds.) (2019). Poemario de Juan Elías Carrera o Necul: Texto mapuche del siglo XIX. Ediciones Comunidad de Historia Mapuche.

Cavada, Francisco J. (1914). Chiloé y los chilotes: Estudios de folklore y lingüística de la provincia de Chiloé (República de Chile) acompañados de un vocabulario de chilotismos y precedidos de una breve reseña histórica del archipiélago. Universitaria

Byron, John (1955). El naufragio de la fragata Wager. Zig-Zag.

Cañas Pinochet, Alejandro (1907 a). La lengua veliche: Su probable origen. Revista Chilena de Historia Natural, vol. XI, p. 5-24.

_ (1907 b). La lengua veliche: Sus caracteres principales. Revista Chilena de Historia Natural, vol. XI, p. 25-89.

— (1907 c). La poesía en los pueblos primitivos de América. Revista Chilena de Historia Natural, vol. XI, p. 91-168.

Darwin, Charles (1925). Diario del viaje de un naturalista alrededor del mundo. Calpe, 2 vols.

De Azúa e Iturgoyen, Pedro Felipe (1846). Informe del excelentísimo señor obispo de la Concepción sobre los curatos de la diócesis (1744). Claude Gay (ed.), Documentos sobre la Historia, la Estadística y la Geografía. (pp. 513-531). Casa del autor / Museo de Historia Natural de Santiago, vol. I.

De Beranger, Carlos (1893). Relación geográfica de la provincia de Chiloé. 1773. Ed. Nicolás Anrique. Cervantes.

De Goizueta, Miguel (1852). Viaje al descubrimiento del estrecho de Magallanes (1558). Ed. Claude Gay. Documentos sobre la Historia, la Estadística y la Geografía. (pp. 55-98). Casa del autor / Museo de Historia Natural de Santiago, vol. II. Orig. Archivo General de Indias, Sevilla.

De Moraleda, José (1786/96/1888). Exploraciones geográficas e hidrográficas. Santiago de Chile: Imprenta Nacional. Vol xxiv 533 mapa. Introducción (p. v-xix) de Diego Barros Arana. Orig. Depósito Hidrográfico de Madrid. 
De Olaverria, Miguel (1852). Informe sobre el reino de Chile, sus indios y sus guerras (1594). Ed. Claude Gay. Documentos sobre la Historia, la Estadística y la Geografía. (pp. 13-54). Casa del autor/Museo de Historia Natural de Santiago. Vol. II. Historia Física y Política de Chile. Orig. Archivo General de Indias, Sevilla.

De Rosales, Diego (1877/1878). Historia general del reino de Chile: Flandes indiano. Imprenta del Mercurio, 3 vols.

De Santa María, Antonio Narciso (1995). Isla de Chiloé. Ed. Francisco de Solano. Relaciones geográficas del reino de Chile: 1756. Consejo Superior de Investigaciones Científicas, Centro de Estudios Históricos, Departamento de Historia de América / Universidad Internacional SEK, col. Tierra nueva e cielo nuevo, $n^{\circ} 33: 261-275$.

De Torres, Diego (1927). Primera carta anua (1609). Documentos para la Historia Argentina. t. XIX: Iglesia: Cartas anuas de la Provincia del Paraguay, Chile y Tucumán, de la Compañía de Jesús (1609-1614). (pp. 3-39). Facultad de Filosofía y Letras \& Instituto de Investigaciones Históricas.

De Vivar, Jerónimo (1558/1979). Crónica y relación copiosa y verdadera de los reinos de Chile. Colloquium, col. Biblioteca Ibero-Americana. $\mathrm{N}^{\mathrm{o}} 27$.

Febrès, Andreu (1764/1765). Arte de la lengua general del reino de Chile. Calle de la Encarnación.

Delfín, Federico (1888). El río Palena: Apuntes para su historia natural. El Progreso, vol. I: 67-75, 150-154, 220-231, 370-377, 443-451, 625-632.

Ferrofino, Juan Bautista (1927). Misión de Chiloé (1611). En: Diego de Torres. “Tercera carta anual". Documentos para la Historia Argentina, t. XIX: Iglesia: Cartas anuas de la Provincia del Paraguay, Chile y Tucumán, de la Compañía de Jesús (1609-1614). (pp. 107-120). Facultad de Filosofía y Letras \& Instituto de Investigaciones Históricas.

García Huidobro, Carlos (1864). Provincias meridionales de Chile: Su descripción según un viaje hecho a ellas. Anales de la Universidad de Chile. Comunicación a la Facultad de Ciencias Matemáticas y Físicas, vol. XXV: 439-489.

García Martí, José (1800). Carta a Lorenzo Hervás y Panduro: Bolonia, 31 de octubre de 1783. En: Lorenzo Hervás y Panduro. Catálogo de las lenguas de las naciones conocidas, vol. I: Lenguas y naciones americanas. (pp. 125-127). Imprenta de la Administración del Real Arbitrio de Beneficencia.

García Ramón, Alonso (1846). Carta al rey de España: Concepción, 12 de abril de 1607. Ed. Claude Gay (ed.), Documentos sobre la Historia, la Estadística y la Geografia. (pp. p. 160-171). Casa del autor/Museo de Historia Natural de Santiago, vol. I. Original Archivo de Indias, Sevilla.

González de Agüeros, Pedro (1781a). Descripción historial de la provincia y archipiélago de Chiloé en el reino de Chile y obispado de la Concepción. Benito Cano. 
(1791b). Misiones y expediciones en la provincia y archipiélago de Chiloé

(1791). Ed. José Toribio Medina. Biblioteca Hispano-Chilena: 1523-1817. (pp. 182-184). Casa del autor, vol. II, 1898

González de Nájera, Alonso (1866). Desengaño y reparo de la guerra del reino de Chile. Imprenta de la viuda de Calero, Colección de Documentos Inéditos para la Historia de España.

Grupo Especial de Expertos sobre las Lenguas en Peligro/Unesco (2003). Vitalidad y peligro de desaparición de las lenguas. Unesco, Documento adoptado por la Reunión Internacional de Expertos sobre el programa de la Unesco "Salvaguardia de las Lenguas en Peligro", 10-12 de marzo.

Guarda, Gabriel (2002). Los encomenderos de Chiloé. Ediciones Universidad Católica de Chile.

Herckmans, Elias (1647). Vocabula chilensia. En: Caspar van Baerle. Rerum per octennium in Brasilia et alibi nuper gestarum, sub prafectura illustrissimi comitis. (pp. 283-289). Joanuis Blaev.

Juliet, Carlos (1870). "Informe al ministro de Marina" Anales de la Universidad de Chile, vol. XXXVI: 104-109.

Juzgado de Ancud (1960). Proceso de los brujos de Chiloé (1881). Anales Chilenos de Historia de la Medicina. Año II, vol. 1: 124-162.

Lenz, Rudolf (1912). Tradiciones e ideas de los araucanos acerca de los terremotos. Anales de la Universidad de Chile. Vol. CXXX, mayo-junio: 753-771.

Maldonado Coloma, Roberto (1898). Parte al comandante de la Pilcomayo, Froilán González (1894). Froilán González, Exploraciones hidrográficas de la cañonera Pilcomayo en la costa sur de la República. Anuario Hidrográfico de la Marina de Chile, vol. XXI: 97-109.

Mariño de Lobera, Pedro (1960). Crónica del reino de Chile. Atlas, 1960, p. 227-562.

Osorio de Escobar, Diego (1819). Informe sobre el puerto de Valdivia (1640). Continuación del Almacén de frutos literarios. (pp. 267-274). Imprenta de Repullés. Tomo VIII, n ${ }^{\circ} 48,5$ de julio.

Philippi, Federico (1880). Viaje a Chiloé. Anales de la Sociedad Científica Argentina. Tomo X, $\mathrm{n}^{\mathrm{o}} 1$.

Reino de España (1870). Real Cédula: Aranjuez, 10 de mayo de 1770. La Revista de Buenos Aires. Vol. VIII, no 89: 46-51.

Reino de España (1789). Instrucción que deberá observar don Pedro Cañaveral, gobernador político y militar de la provincia e islas de Chiloé. - Archivo General de Indias, Sevilla, "Chile", 217. - Suscrita en Madrid, 24 de junio de 1789.

Silva Castro, Raúl (1953). Introducción. Censo de 1813. (pp. vii-xx). Imprenta de Chile. 
Simpson, Enrique M. (1875). Vocabulario payo y antiguo chono (1872). Enrique M. Simpson. Exploraciones hechas por la corbeta Chacabuco en los archipiélagos de Guaitecas, Chonos y Taitao. Anuario Hidrográfico de la Marina de Chile. Vol. I: 104. Suárez, José B. (1854). Informe sobre el estado y necesidades de la instrucción primaria en la provincia de Chiloé. El Monitor de las Escuelas Primarias. Tomo II: 302-314.

Urbina Burgos, Rodolfo (1988). Chiloé, foco de emigraciones. Chiloé y su influjo en la XI Región: II Jornadas territoriales. (pp. 31-46). Universidad de Santiago, Instituto de Investigaciones del Patrimonio Territorial de Chile.

— (1990). La rebelión indígena de 1712: Los tributarios de Chiloé contra la encomienda. Tiempo y espacio, Universidad del Biobío, Facultad de Educación. $\mathrm{N}^{\mathrm{o}} 1: 73-86$.

Urízar Garfias, Fernando (1835). Repertorio chileno: Año de 1835. Imprenta Araucana. Vásquez, Ángel (1870). Plantas y algunos otros productos notables de Chiloé. Ángel Vásquez, Apuntes sobre el Archipiélago de Chiloé. (418-420). La Estrella de Chile. Apéndice.

Vidal Gormaz, Francisco (1971). Exploración de la costa de Llanquihue y archipiélago de Chiloé. Imprenta Nacional, 168.

— (1872). Exploración del seno de Reloncaví, lago de Llanquihue y río Puelo. Imprenta Nacional, 179, 6 h. láms.

Weber, Alfred (1903). Chiloé: Su estado actual, su colonización, su porvenir. Mejía, 194, mapa. 